\title{
Jane Marie Ruth Gillett
}

Dr. Jane Gillett, a neurologist at McMaster University in Hamilton, passed away on February 16, 2011 in her 56th year from cancer. Most of us did not know she was ill until hearing of her death.

Jane Gillett was a remarkable individual. Her first profession was in speech pathology and she organized a successful, thriving corporation of speech pathologists before she decided to go to medical school. She then did residencies in adult neurology at the University of Western Ontario and then in pediatric neurology at the University of Toronto.

Dr. Gillett was a brilliant neurologist who not only gave excellent care individually to her patients, but with her superb organizational skills formed organizations and support groups for more comprehensive management of head injury victims. After her residencies she returned to London, Ontario where she formed the Pediatric Acquired Brain Injury Community Outreach Program and was the Medical Director of the inpatient Pediatric Acquired Brain Injury Program at the Children's Hospital of Western Ontario for 12 years. She then served as Medical Director of the Acquired Brain Injury Program at Hamilton Health Sciences and as an Associate Professor at McMaster University. She was a Member of the Canadian Association of Child Neurology, the International Society for the Study of Acquired Brain Injury, the American Academy for Neurorehabilitation and the North American Brain Injury Society. Dr. Gillett also founded the Paediatric Head Injury Group of Ontario (PHIGO). Recently she was appointed the chair of the knowledge mobilization committee of the Ontario Neurotrauma Foundation.

Jane also had a wicked sense of humor and with her intelligence was able to put things into perspective and to not take life too seriously. She will be sadly missed, but physicians, allied health care workers and patients will continue to benefit from her example and the organizational, supportive structures that she established and fostered.

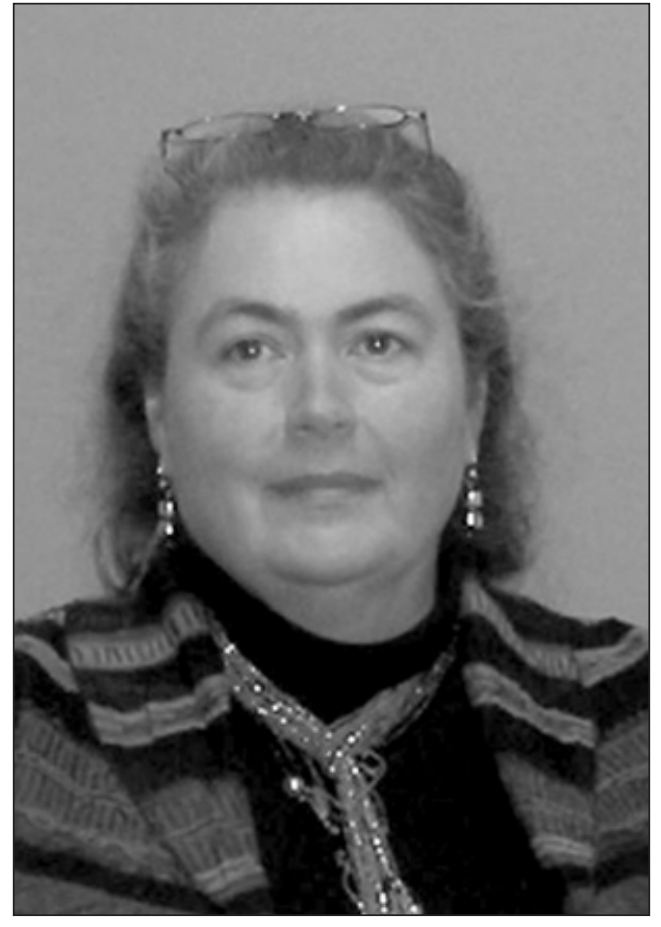

G. Bryan Young Department of Clinical Neurological Sciences London Health Sciences Centre London, Ontario, Canada 